\section{SLE-DAS: ready for routine use?}

It is with great interest that we read your recently published article, 'Derivation and validation of the SLE disease activity score (SLEDAS).${ }^{1}$ Systemic lupus erythematosus (SLE) is a multisystem disease with protean clinical manifestations. The disease runs a variable course, with no reliable co-relation between various organ involvement and biochemical markers. There have been numerous attempts to document diseases activity in an objective manner, with only limited success. ${ }^{2}$ In this article, the authors' effort to translate the disease activity in SLE into a more responsive score by quantifying arthritis, proteinuria, leucopenia and thrombocytopenia seems promising. However, we would like to raise a few points of concern.

1. The median physician global assessment (PGA) and systemic lupus erythematosus disease activity index 2000 (SLEDAI$2 \mathrm{~K})$ scores in both the derivation and validation cohorts suggest that they were of low disease activity group; hence, the validity of the score in a more active disease group may not be the same. ${ }^{34}$

2. Is proteinuria alone sufficient to asses renal disease activity?

a. Renal manifestations, such as the presence of urinary RBCs, WBCs and cellular casts, are not factored into the score, even though their presence has got a significant prognostic role and is a part of SLEDAI-2K.

b. Proteinuria may not always indicate disease activity as it can also be a result of irreversible scarring in the kidney. Hence, we believe proteinuria in the presence of active sediments is of higher specificity for disease activity.

3. Ongoing requirement of glucocorticoids is another important factor that could have been given weightage, as it indirectly reflects the physicians' perspective of activity, and may also alter with magnitude of organ involvement.

4. Although rare, severe manifestations, such as lupus pancreatitis, need consideration as they reflect severe disease.

We tried to address the concern of performance of SLE disease activity score (DAS) in a cohort of lupus nephritis with high disease activity. In the same analysis, we tried to look into the effect of non-inclusion of urinary sediment in SLE-DAS. Patient characteristics and disease activity measures are presented in table 1 and table 2 respectively.

We retrospectively calculated SLE-DAS for 41 patients of lupus nephritis at baseline, 3 months and 6 months.

To assess the validity of SLE-DAS in our population, we compared the global scores of SLE-DAS with PGA and SLEDAI using Spearman's correlation. At baseline, SLE-DAS score showed moderate positive correlation with SLEDAI-2K $(\mathrm{r}=0.70, \mathrm{p}<0.001)$ and a weak positive correlation with PGA $(\mathrm{r}=0.32, \mathrm{p}<0.05)$. At 6 months follow-up, SLE-DAS score showed strong positive correlation with SLEDAI-2K ( $r=0.92$, $\mathrm{p}<0.001)$ and a weak positive correlation with PGA $(\mathrm{r}=0.35$, $\mathrm{p}<0.05)$. This may imply that SLE-DAS has got a better correlation with SLEDAI-2K when the disease activity is low and its performance among patients of high disease activity may not be robust.

Renal component of SLE-DAS was calculated and the effect size was determined for renal component of SLEDAI-2K and

\begin{tabular}{ll}
\hline Table $1 \quad$ Patient characteristics $(\mathrm{N}=41)$ & \\
\hline Gender, female, $\mathrm{n}(\%)$ & $39(95.12)$ \\
\hline Age (years), mean (SD) & $30(8.4)$ \\
\hline Disease duration (months), median (IQR) & $15(3.5-32.0)$ \\
\hline
\end{tabular}

Table 2 Disease activity scores of patients included $(\mathrm{N}=41)$

\begin{tabular}{lccc}
\hline $\begin{array}{l}\text { Disease activity } \\
\text { score }\end{array}$ & Baseline & At 3 months & At 6 months \\
\hline PGA, median (IQR) & $2.3(2.1-2.6)$ & $1.2(0.8-1.9)$ & $1.0(0.0-1.0)$ \\
$\begin{array}{l}\text { SLEDAl-2K, median } \\
\text { (IQR) }\end{array}$ & $23.0(18.0-28.5)$ & $6.0(3.0-8.0)$ & $2.0(2.0-6.0)$ \\
$\begin{array}{l}\text { SLE-DAS, median } \\
\text { (IQR) }\end{array}$ & $28.14(21.81-38.98)$ & $7.37(1.32-9.84)$ & $2.08(0.74-8.39)$ \\
$\begin{array}{l}\text { SLE-DAS renal, } \\
\text { median (IQR) }\end{array}$ & $10.15(7.73-12.07)$ & $6.53(0-8.43)$ & $0(0-6.70)$ \\
$\begin{array}{l}\text { SLEDAI-2K renal, } \\
\text { median (IQR) }\end{array}$ & $12.0(8.0-12.0)$ & $4.0(0.0-4.0)$ & $0.0(0.0-4.0)$ \\
\hline $\begin{array}{l}\text { SLE-DAS, systemic lupus erythematosus disease activity score. } \\
\end{array}$ &
\end{tabular}

SLE-DAS using standardised test $[\mathrm{r}=\mathrm{Z} / \operatorname{sqrt}(\mathrm{n} 1+\mathrm{n} 2)]$. Effect sizes were interpreted using Cohen's criteria as large $(\geq 0.5)$, medium $(\geq 0.3)$ or small $(\geq 0.1) .^{5}$ Among our patients, renal SLE-DAS significantly reduced from median (IQR) 10.15 $(7.73-12.07)$ at baseline to $0(0-6.70)$ at 6 months. The effect size for the renal component of both SLE-DAS and SLEDAI-2K were large at -0.572 and -0.602 , respectively $(\mathrm{p}=0.18)$, showing good sensitivity for change.

We had a single patient with persistent proteinuria with no active urinary sediments at the end of the induction phase for proliferative lupus nephritis. The patient had normal complements, low anti-dsDNA titer and her baseline renal biopsy showed increased chronicity score. Her renal component of SLE-DAS score was 13.19 at baseline and 10.17 due to contribution from proteinuria at 6 months whereas her renal component of SLEDAI-2K had fallen from 12 to 4 . Though the observation was in a single patient, the fact remains that proteinuria alone is not specific for active disease. Using SLEDAS in such a scenario would portray a falsely high diseases activity and a word of caution is necessary.

Though SLE-DAS is a brave and innovative attempt in quantifying SLE disease activity, there may be no added advantage over the existing SLEDAI-2K score in its current state. Its performance in high disease activity and in those without proteinuria but with active sediments in the urine will have to be reconfirmed.

\section{Anoop Mathew $\odot$, Kavadichanda G Chengappa, Sanket Shah, Vir Singh Negi}

Department of Clinical Immunology, Jawaharlal Institute of Postgraduate Medical Education and Research (JIPMER), Puducherry, India

Correspondence to Dr Vir Singh Negi, Clinical Immunology, JPMER, Puducherry 605 006, India; vsnegi22@yahoo.co.in

Contributors VSN, AM, KGC and SS contributed to the conception and design, acquisition of data, analysis and interpretation of the data and final approval of the version to be published. AM and SS drafted the article. VSN critically revised the article for important intellectual content. VSN, AM, KGC and SS agree to be accountable for all aspects of the work in ensuring that questions related to the accuracy or integrity of any part of the work are appropriately investigated and resolved.

Funding The authors have not declared a specific grant for this research from any funding agency in the public, commercial or not-for-profit sectors.

Competing interests None declared.

Patient consent for publication Not required.

Provenance and peer review Not commissioned; internally peer reviewed.

(C) Author(s) (or their employer(s)) 2020. No commercial re-use. See rights and permissions. Published by BMJ.

Check for updates 
To cite Mathew A, Chengappa KG, Shah S, et al. Ann Rheum Dis 2020;79:e116.

Received 15 May 2019

Accepted 19 May 2019

Published Online First 24 May 2019

\section{S Linked}

- http://dx.doi.org/10.1136/annrheumdis-2019-215794

Ann Rheum Dis 2020;79:e116. doi:10.1136/annrheumdis-2019-215704

ORCID iD

Anoop Mathew http://orcid.org/0000-0003-0778-3151

\section{REFERENCES}

1 Jesus D, Matos A, Henriques C, et al. Derivation and validation of the SLE disease activity score (SLE-DAS): a new SLE continuous measure with high sensitivity for changes in disease activity. Ann Rheum Dis 2019;78:365-71.

2 Mikdashi J, Nived O. Measuring disease activity in adults with systemic lupus erythematosus: the challenges of administrative burden and responsiveness to patient concerns in clinical research. Arthritis Res Ther 2015;17.

3 Petri M, Genovese M, Engle E, et al. Definition, incidence, and clinical description of flare in systemic lupus erythematosus. A prospective cohort study. Arthritis Rheum 1991;34:937-44.

4 Gladman DD, Ibañez D, Urowitz MB. Systemic lupus erythematosus disease activity index 2000. J Rheumatol 2002;29:288-91.

5 Cohen J, Analysis SP. Statistical power analysis. Curr Dir Psychol Sci 1992;1:98-101. 